2. Urschel JD, Horan TA, Unruth HW. Plasma cell granuloma of the lung. J ThOrac Cardiovasc Surg 1992; 104:870-5.

3. Scott L, Blair G, Taylor G, Dimmick J, Fraser G. Inflammatory pseudotumor in children. J Pediatr Surg 1988; 23:755-8.

4. Monzon CM, Gilchrist GS, Burgert EO, et al. Plasma cell granuloma of the lung in children. Pediatrics 1982;70:26874.

5. Mandelbaum I, Brashear RE, Hull MT. Surgical treatment and course of pulmonary pseudotumor (plasma cell granuloma). J Thorac Cardiovasc Surg 1981;82:77-82.

\section{Malignant fibrous histiocytoma of the chest wall developing after pleuropneumonectomy performed for tuberculous pyothorax: Report of an unusual case}

\section{To the Editor:}

Reports indicate the onset of malignant fibrous histiocytoma (MFH) in the chest wall after old pleuritis or pyothorax, ${ }^{1}$ radiotherapy, ${ }^{2}$ or burns, ${ }^{3}$ but they rarely indicate that $\mathrm{MFH}$ develops after operations. ${ }^{4}$ We treated a patient who had contracted tuberculous pleuritis and tuberculous pyothorax and in whom MFH developed in the chest wall 16 years after pleuropneumonectomy carried out for tuberculous pyothorax.

The patient was a 69-year-old man with cough and pyrexia. When he was 19 years old, complete rest had been prescribed for the treatment of left-sided tuberculous pleuritis. At the age of 53 years, he had undergone pleuropneumonectomy for leftsided tuberculous pyothorax at our hospital. In March 1992, cough and fever $\left(38^{\circ} \mathrm{C}\right)$ appeared. He was admitted to the department of internal medicine of our hospital and received combination drug therapy with isoniazid (INH), rifampicin (RFP), etambutol (EB), and various antibiotics for about 2 months. Despite these medications, remittent fever persisted.

Repeated thoracentesis at the department of internal medicine yielded no materials sufficient for bacteriological examination. Inasmuch as no definitive diagnosis was established, he was referred to our department for open chest biopsy on May 15, 1992. After he was transferred to our department, laboratory examination revealed an erythrocyte count of $348 \times 10^{4} / \mathrm{mm}^{3}$, a hematocrit value of $27.1 \%$, and a hemoglobin level of 8.9 $\mathrm{gm} / \mathrm{dl}$, indicating anemia. Anemia had progressed during the 2 months after the initial examination at the department of internal medicine. In addition, marked inflammation was apparent: the leukocyte count was $9800 / \mathrm{mm}^{3}$, erythrocyte sedimentation rate $143 \mathrm{~mm} / \mathrm{hr}$, and C-reactive protein $22.6 \mathrm{mg} / \mathrm{dl}$. The purified protein derivative test was $0 / 22 \times 20 \mathrm{~mm}$. Roentgenogram of the chest showed that the left lung was absent because of past pleuropneumonectomy. The left sixth rib was absent, and the seventh rib was deformed. Comparison with the previous chest $x$-ray films indicated that the defect and deformity were due to the operation carried out 16 years previously. A computed tomographic scan of the chest visualized marked deformity of the thorax and ribs. A wall with a uniform thickness on both the pleural and mediastinal sides surrounded the thoracic cavity, which contained no obvious protruding tumor. By gallium 67 scintigraphy, an image of abnormal accumulation was observed in the area corresponding to the left thoracic cavity. In summary, no abscess could be aspirated by thoracentesis, fever did not subside after antibiotic administration, and the chest roentgenogram showed no air fluid level. These findings did not suggest bacterial infection, and the reaction to the purified protein derivative test was too weak to suggest active tuberculosis. Because the patient became anemic in a short period of time, a malignant tumor of the chest wall was suspected, and open chest biopsy was performed on June 5, 1992.

A left posterolateral incision revealed the intercostal spaces to be narrowed and to show yellowish white thickening. A portion of the parietal pleura was resected through the narrowed fifth intercostal space. Prompt pathologic examination revealed sarcomatoid malignant cells. Thoracotomy was done in the fifth intercostal space to collect tissue from the thoracic cavity. Malignant cells were also present in this area. The yellowish white intercostal thickening involved the other intercostal spaces and ribs. The tumor in the thoracic wall was thought to have invaded the mediastinal side. Because a curative operation was judged to be impossible because of the extensive lesion, part of the third, fourth, and fifth ribs, the neighboring parietal pleu$\mathrm{ra}$, and the tissue in the thoracic cavity were collected to end the surgical procedure. Specimens of the parietal pleural tissue were stained with hematoxylin and eosin. Low-power magnification of the specimens visualized a tumor in which spindle cells grew while forming a storiform pattern. The tumor appeared to be a polymorphic sarcoma marked by atypical giant cells. Highpower magnification of the image revealed tumor cells consisting of fusiform fibroblastic cells and slightly oval histiocytic cells. These cells were positive in $\alpha_{1}$-antichymotrypsin staining but were negative in all of cytokeratin (KL-1), epithelial membrane antigen (EMA) and S-100 protein staining. These findings led to a histologic diagnosis of $\mathrm{MFH}$. Histologic findings of the resected bone also showed invasion of the bone marrow by the MFH.

Postoperatively, three courses of CYVADICT therapy (cyclophosphamide, vincristine, doxorubicin, and dactinomycin) were given. Subsequently, the chemotherapy could not be continued because of debilitation. The patient died of general debilitation caused by tumoral fever 5 months after the operation. Consent for autopsy was not obtained.

The common sites of occurrence of MFH include the proximal regions of the extremities, such as the thigh, buttock, upper arm and shoulder, and the posterior peritoneum. The chest wall is a rare site of origin. ${ }^{5}$ Reports indicate that MFH develops 8 to 14 years after radiotherapy, ${ }^{2} 16$ to 25 years after burns, ${ }^{3,6}$ and in the cicatricial wound 6 to 8 years after the operation. ${ }^{4}$ It also has occurred 10 months after the onset of bone marrow infarction $^{7}$ and in the area having a vascular prosthesis 1 year later. ${ }^{8}$ Malignant tumors frequently occur in the chest wall and thoracic cavity after chronic pleuritis and pyothorax. Epithelial tumors include squamous cell carcinoma, and nonepithelial tumors include malignant lymphoma, liposarcoma, angiosarcome, rhabdomyosarcoma, malignant mesothelioma, and MFH. Myoui and associates ${ }^{1}$ found soft tissue sarcoma originating in the chest wall or thoracic cavity in two of 134 patients with tuberculous pyothorax and reported that the prevalence was about 1000 times that among normal individuals. They also reported that $65 \%$ of patients with MFH originating in the thoracic cavity had histories of chronic pleuritis or pyothorax, drawing attention to the relationships between histories of these disorders and the onset of MFH. The reported interval between 
chronic pleuritis or pyothorax and the outbreak of soft tissue sarcoma is 15 to 50 years. ${ }^{1}$

Our patient had had tuberculous pleuritis 50 years previously and had undergone pleuropneumonectomy for tuberculous pyothorax at our department 16 years earlier. This operation involved en bloc resection of parts of both lungs and the parietal, mediastinal, and diaphragmatic pleurae. Since then, tuberculous pleuritis or pyothorax had not recurred. A surgically resected pleura regenerates, during which histiocytes and fibroblastic cells play an important role. We think that in rare cases these two types of cells and undifferentiated mesenchymal cells become malignant, causing MFH. Chronic inflammation has been found to develop in a surgical wound, ${ }^{3}$ and $\operatorname{Tan}^{9}$ reported the occurrence of fibrosarcoma in a laparotomy wound. In our patient, postoperative chronic inflammation caused by surgery and slight residual tuberculosis may have led to pleural formation, inducing the onset of MFH. The mechanism of onset of malignant tumors as a result of malignant cellular changes remains to be clarified.

\section{Iwao Takanami, $M D^{a}$ \\ Tetsuo Imamura, $M D^{b}$ \\ Noboru Morota, $M D^{a}$ \\ Susumu Kodaira, $M D^{a}$ \\ First Department of Surgery ${ }^{a}$ Department of Pathology $y^{b}$ \\ Teikyo University of Medicine Tokyo, 173, Japan}

\section{R EFERENCES}

1. Myoui A, Aozasa K, Iuchi K, Mori T, Yamamoto S, Kuratsu S. Soft tissue sarcoma of the pleural cavity. Cancer 1991;68:1550-4.

2. Chowdhury LN, Swerdlow MA, Willington J, Kathpalia S, Desse RK. Postirradiation malignant fibrous histiocytoma of the lung: demonstration of $\alpha_{1}$-antitrypsin-like material in neoplastic cells. Am J Clin Pathol 1980;74:820-6.

3. Yamamura T, Ozasa K, Honda T, Akada A, Maeda M, Sano S. Malignant fibrous histiocytoma developing in a burn scar. Br J Dermatol 1984;110:725-30.
4. Inoshita T, Youngberg GA. Malignant fibrous histiocytoma arising in previous surgical sites. Cancer 1984;53:176-82.

5. Weiss SW, Enzinger FM. Malignant fibrous histiocytoma: an analysis 200 cases. Cancer 1978;41:2250-66.

6. Cruickshank AH, McConnel EM, Miller DG. Malignancy in scars, chronic ulcers and sinuses. J Clin Pathol 1963; 16:573-80.

7. Bader H, Spohner F, Gerlitzky W, Meyer D. Malignant fibröses histiozytom nach suprakondylärer oberschenkelfroktur. Deutsch Med Wochenschr 1981;106:336-9.

8. Weinberg DS, Maini BS. Primary sarcoma of the aorta associated with avascular prosthesis: a case report. Cancer 1980;46:398-402.

9. Tanz SS. Fibrosarcoma following single trauma: report of a case. J Int Coll Surg 1957;27:620-6.

\section{Aortoplasty for aortic regurgitation with ventricular septal defect}

To the Editor:

Valvuloplasty is commonly performed for treatment of aortic regurgitation with ventricular septal defect (VSD) in younger patients, and several conservative procedures for aortic valve repair have been reported. ${ }^{1-3}$ In this study, we observed patients who underwent aortoplasty, and we discuss the mid-term clinical results of this operation.

Eleven patients underwent aortoplasty between March 1976 and January 1988. The age at operation ranged from 2 to 21 years (mean 7.2 years). The degree of aortic regurgitation was determined from aortic root angiography and was classified by the criteria of Sellers and associates. ${ }^{4}$ Preoperative regurgitation was grade II in one and grade III in ten patients. The predominant location of the VSD was conal in ten and perimembranous in one patient. The site of the prolapsed aortic valve was mainly in the right coronary cusp in all patients. Ascending aortic and bicaval cannulation was used for all operations. Continuous coronary perfusion was used before 1978; since then, cardiac arrest has been induced with crystalloid cardioplegic solution

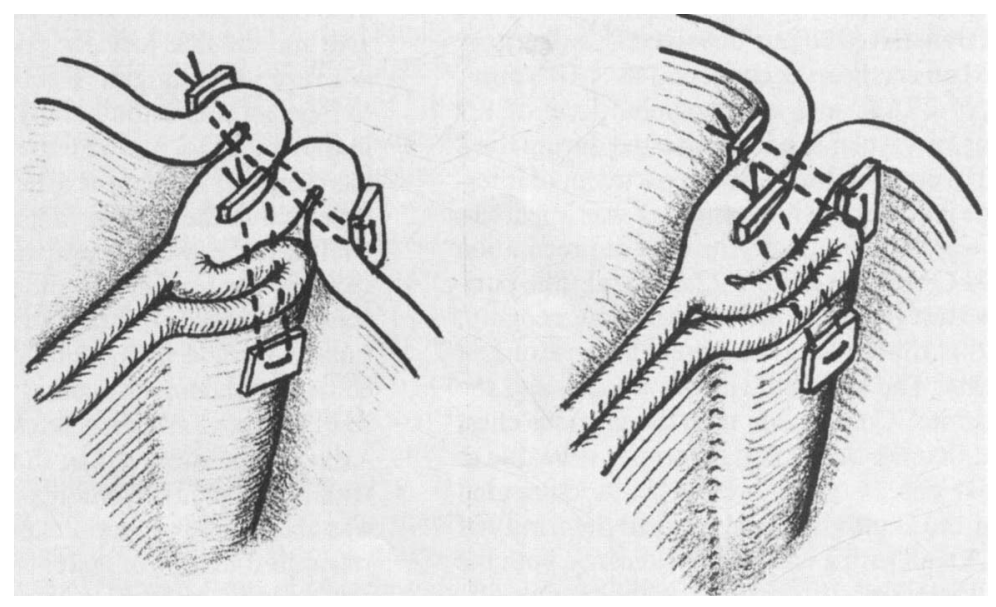

Fig. 1. Aortoplasty. 